\title{
Determinants of Using Alternative to Single-Use Plastic Bags
}

Norzalina Zainudin, Wai Yi Qi, Jasmine Leby Lau, Zubaidah Harun \& Nurkaliza Khalid

To Link this Article: http://dx.doi.org/10.6007/IJARBSS/v11-i11/11659

DOI:10.6007/IJARBSS/v11-i11/11659

Received: 13 September 2021, Revised: 16 October 2021, Accepted: 30 October 2021

Published Online: 11 November 2021

In-Text Citation: (Zainudin et al., 2021)

To Cite this Article: Zainudin, N., Qi, W. Y., Lau, J. L., Harun, Z., \& Khalid, N. (2021). Determinants of Using Alternative to Single-Use Plastic Bags. International Journal of Academic Research in Business and Social Sciences, 11(11), 1753-1766.

Copyright: (C) 2021 The Author(s)

Published by Human Resource Management Academic Research Society (www.hrmars.com)

This article is published under the Creative Commons Attribution (CC BY 4.0) license. Anyone may reproduce, distribute, translate and create derivative works of this article (for both commercial and non0-commercial purposes), subject to full attribution to the original publication and authors. The full terms of this license may be seen at: http://creativecommons.org/licences/by/4.0/legalcode

Vol. 11, No. 11, 2021, Pg. $1753-1766$

Full Terms \& Conditions of access and use can be found at http://hrmars.com/index.php/pages/detail/publication-ethics 


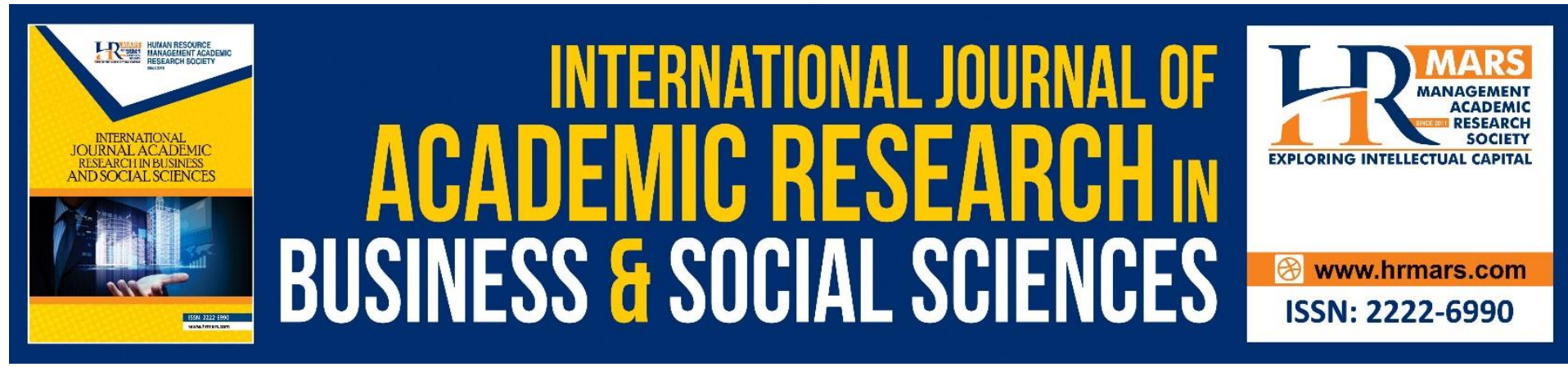

\title{
Determinants of Using Alternative to Single-Use Plastic Bags
}

\author{
Norzalina Zainudin ${ }^{1,2}$, Wai Yi Qi ${ }^{1}$, Jasmine Leby Lau ${ }^{1}$, Zubaidah \\ Harun $^{3}$, \& Nurkaliza Khalid ${ }^{4}$
}

Department of Resource Management and Consumer Studies ${ }^{1},{ }^{2}$ Sustainable Consumption Research Centre of Excellence ${ }^{2}$, Faculty of Human Ecology, University Putra Malaysia. UPM Serdang, Selangor, Malaysia, ${ }^{3}$ Department of Natural Resource Industry, Faculty of Forestry \& Environment, University Putra Malaysia, UPM Serdang, Selangor, Malaysia, ${ }^{4}$ Matriculation Centre, Selangor International Islamic University College.

Email: norzalina@upm.edu.my

\begin{abstract}
The environmental tax has been used as an effective tool in achieving desired behaviour changes. This paper evaluates the factors that contribute to the usage of alternatives to the use of single-use plastic bags after the implementation of 20 cents charge on the plastic used by the government of Malaysia. The sample size of 200 respondents in Bangi and Putrajaya was chosen by using convenience sampling with face-to-face questionnaires. The data then were analysed using descriptive analysis (SPSS) and structural equation model (SEM) with AMOS. The result indicates that 76 percent of consumers are willing to use an alternative to plastic bags, such as using their own shopping bag or trolley. Analysis SEM found a 20 cents charge on plastic bag use and subjective norms have significant influence on the use of an alternative to a single-use plastic bag. These findings contribute to the strengthening of the instruments capable of producing behavioural changes at a minimal cost. Therefore, marketbased instrument as a 20 cents tax on the plastic used for pollution control and natural resource management is an increasingly important part of environmental policy tools in Malaysia and there is high potential in their use and effectiveness.
\end{abstract}

Keywords: Environmental Tax, Polluter Pays Principle, Single-used Plastic Bag, 20 Cents Charge, Behavior

\section{Introduction}

Plastic bag wastes pose big environmental pollutions and health problems to animals and humans. In 2014, approximately 8.5 billion plastic bags were used by consumers, which accounted for around 58,000 tonnes of plastic (Waste and Resources Action Program, WRAP, 2015). Statistic for a country, such as India shows that the share of plastic waste in a total of solid waste has thus increased from 0.6 percent in 1996 to 9.2 percent in 2005 (World Bank, 2008). In Turkey also found a heavy use of plastic which each people uses an average of 312 plastic bags every year (Hurriyet, 2015). Similar case as Malaysians on average produce an estimate of 19,000 tonnes of solid waste annually and plastic waste represents 24 percent of 
total solid waste (Asmuni et al., 2015). All the numbers stated by these countries are shown as agree with the estimation from the global warming white paper which said over 300 plastic bags per person are consumed every year (United Nation Environment Program, UNEP, 2018). With the current situation, waste management becoming more spatially and purpose-wise complex. Waste management operators, planners, and government continue to face the challenge of providing people with a good waste management system. The government of a country facing the high cost of managing waste every year. A highly populated country, China stated as the cost to regulate white pollution was up to $18,500,000$ Yuan each year. Data in Beijing itself reported as 3 percent of house refuse is wasted plastic wrap materials with a quantity of 140,000 tons each year (Chan et al., 2007). A huge amount of free plastic bags is consumed every year by everyone. Plastic bag usage is likely to become a habitual behavior that is activated automatically. The concept of 'Free plastic bags' was a normal provision bearing no cost on the environment as people viewed free plastic carrier bags as inadequate in economic value. Hence, the public does not consider their true cost of environmental harm (Akulian et al., 2007). Free of charge plastic bags have caused negative environmental impacts because plastic bags are made from non-renewable resources and it will take hundreds of years for plastic to weaken (Muthu et al., 2011). The policies to impose charges for plastic bag consumption in the name of environmental good practices may not be consumer-friendly but decreasing the use of plastic bags is very great, both for saving resources and for creating a green environment. Studies (Zen et al., 2013; Siddique et al., 2008; Convery et al., 2007) show how the decreasing in plastic bag use can work as an efficient environmental activity.

However, the idea of charging for a plastic bags is one course of action that creates a significant challenge on the part of consumer shopping habits, especially during major grocery shopping. The implementation of the plastic bag charges is rather to stimulate consumer behavioral changes, reducing the litter and excessive consumption of plastic (Park, 2009). The consumer will have the choice to avoid paying for the plastic bags which bringing their own grocery bag. The application of the plastic bag policy at the point of sale gives an immediate effect to the consumer behavioral change (Baker, 2010). The combined approach of the levy and regulation on plastic bag use applied in the program is an attempt to educate the public and increase their awareness of the environmental harm of using plastic bags. Several state governments and the federal government of Malaysia have implemented the 'No Plastic Bag Day'. In other countries, they carried similar initiatives such as a ban on the use of plastic bags and the use of plastic bag tax or levy (Kamaruddin \& Yusuf, 2021; Kuppusamay \& Gharleghi, 2015). The use of tax or levy as a price signal can be an important instrument to change consumer behavior and the level of consumer acceptance of its implementation are crucial to its success (Convery et al., 2007). However, while there have been many attempts and plans to decrease the use of plastic bags as carrier bags, not many of them have been assessed in terms of their success or efficiency (Poortinga et al., 2013). The effectiveness of plastic bag charges is usually associated with changes in the behavior of users. One study concluded that the plastic bag tax has not been effective as consumers continue to forget to bring their own plastic bags for shopping (Zen et al., 2013). Poortinga et al (2013) described the effectiveness of the charge similarly, which is through the habit change of consumers towards consciously bringing their own recycle bags.

Just as mentioned before, problem arises when people are still willing to pay about the RM 0.20 charge and thus continue to use those plastic bags that have proven to be very difficult 
to decay. Also, some people have a big doubt about both the importance of conserving resources as to compare with self-utility and also doubt the success of this policy. Therefore, the main objective of this work is to verify a multivariate model based on the principles of the structural equation model (SEM), which analyses the impact of different variables and factors identified by the previous studies as linked to the decision process on the alternative use of single-use plastic bags, in a Klang Valley. The debate of 20 cents charge as consider cheap price has been identified as a barrier to the behavior changes. The perceived inconvenience caused by brings own recycle bag has been shown to influence consumers' decision to use plastic bags during shopping. Literature on the use of plastic bags has been predominantly focused on the effectiveness of the tax to improve consumer behavior (Asmuni et al., 2015; Zen et al., 2013; Hong, 2011). In comparison, there have been a limited number of research studies, which focused on the psychological aspect of behavior related to the use of alternatives to the plastic bags during shopping. To the authors' knowledge, none of the past studies have investigated consumers' psychological factors in association with the alternative use of single-use plastic bags during shopping. The present study expands the Theory of Reasoned Action (Fishbein, 1967) in exploring the relationship between 20 cents tax, attitude, subjective norms, and awareness with the usage of alternative to single-use plastic bags on shopping. Hereafter, section 2 outlines the review concepts on single-use plastic bags and 20 cents charge, then follows with theoretical framework in section 3. Section 4 describes the methodology part and results and discussion presented in section 5 , then the final section is a conclusion, limitation and future research.

\section{Single-Use of Plastic Bags and A 20 Cents Charge}

Does charging consumers to pay 20 cents for plastic bag usage effective to reduce pollution? This question is always debating on how environmental tax was used which seeks to change consumer behaviour. The polluter pays principle in this tax system has been used as an effective tool in achieving desired behaviour changes. Single-use concept apply to most plastics that are designed to be thrown away after being used only once. Since the 1950s, the production of plastic has outpaced that of almost every other material due to its versatility and functionality (MESTECC, 2018). Only nine percent of nine billion tonnes of plastic produced in the world has been recycled. Then, most end up in landfills, dumps, or in an open environment (UNEP, 2018). Single-use plastics include any plastics that are commonly used for plastic packaging, carry bags, and any items intended to be used only once before they are thrown away.

As environmental problems related to plastic waste has become a major problem in Malaysia and some studies also highlighted the potential health effects of single-use plastics on humans and animals. More than 60 countries have introduced some measures to curb singleuse plastic waste such as imposing bans and levies. Some countries have imposed a direct ban on single-use plastics and in some other cases, complemented with economic instruments (called a pollution charge or tax or levy). Previous studies (Soares et al., 2010; Asmuni et al., 2019) have shown the role of environmental taxes as a significant economic tool and longterm incentive for protecting the environment.

Malaysia's effort to reduce the use of plastic bags began when the Penang state in 2009 banned the use of plastic bags from shopping stores on Saturday (The Star, 2019). Then in 2010, Selangor followed to ban the use of plastic bags for customers on Saturdays. The stored 
that do not provide plastic bags and customers are encouraged to bring their own carrier bags, or purchase eco-friendly bags. Some stores provide paper bags or synthetic fiber carrier bags that can be reused several times. They reinforced the ban on plastic bags with a charge of 20 cents, which is equivalent to USD0.06 for every plastic bags requested by a retail store customer. The federal government in 2011 then launched the No Plastic Bag Day Campaign throughout Malaysia for each Saturday. With the objective is to reduce the use of plastic bags, all retail outlets, supermarkets, and hypermarkets followed to impose the ban. The use of plastic bags is only allowed for wet markets, restaurants, and night markets for hygiene purposes when carrying wet groceries and food (Zen et al., 2013).

In January 2017, all plastic bags and polystyrene food containers have been fully banned in Selangor and the Federal Territories. The government of Selangor then has banned the use of polystyrene containers and changed the user to be RM 0.20 charge to buy a plastic bag on Saturdays to seven days a week. The Selangor Legislative Assembly in July 2018 said a total of RM1.87 million had been collected from shoppers in Selangor through the RM 0.20 charge for each plastic bag since the 'No Plastic Bag' campaign was executed in the state. The collection, however, only involved supermarkets and food premises that had informed the state government, through their respective trade associations, on their collection of the 20 cents charge between January and May. Of the total, 63.98 percent of the collection was made by supermarket operators, while the rest, by operators of food premises. Many areas would benefit from the 20 cents collected from the sale of plastics bags. The report said when Selangor started its "No Plastic Bag Day" in 2010, the money collected is encouraged to invest into environment-centric programs such as tree planting, edible gardens, and free reusable bags. For example, Tesco stores had planted 202,400 trees, adopted 16 schools for a program that teaches pupils how to grow vegetables, herbs ad fruits, and turned food waste into compost with the money collected from the public (The Star, 2019).

\section{Theoritical Framework}

The Theory of Reasoned Action (TRA), which has been applied previously to predict green consumer behavior, and robustness of the theory has been confirmed (Bamberg, 2003; Kalafatis et al., 1999), is used to explain the antecedents of consumers' alternative use of plastic in shopping. Specifically, this study considers 20 cents tax, attitude, subjective norms, and awareness as an antecedent of the alternative use of single-use plastic bags (Figure 1).

\section{Cents Charge/ Tax}

Martinho (2017) stated that the plastic bags charge in Portugal was found to be efficient at decreasing the use of plastic bags. The researcher mentioned the decrease was around 74 percent, accompanied by an increment in consumption of reusable plastic bags. The paper also suggested that the behavior change occurred not only because of the tax, but also due to alternatives offered by supermarkets and hypermarkets including offering or selling reusable bags instead of a tax on plastic bags. A study by Zen et al (2013) showed that plastic bag tax can be seen as part of consumers' behavior changing process and they found various reactions from the consumer side. The result was that the banning of plastic bags was widely accepted by the public but only in markets but not for other public markets such as night markets. The tax itself is actually able to create a better environment but it requires a much more legislative framework for it to thrive in Malaysia. Therefore, the study hypothesizes that: 
Hypothesis 1 (H1). A 20 cents charge/ tax factor has a significant and positive effects on the use of alternatives to single-use plastic shopping bags.

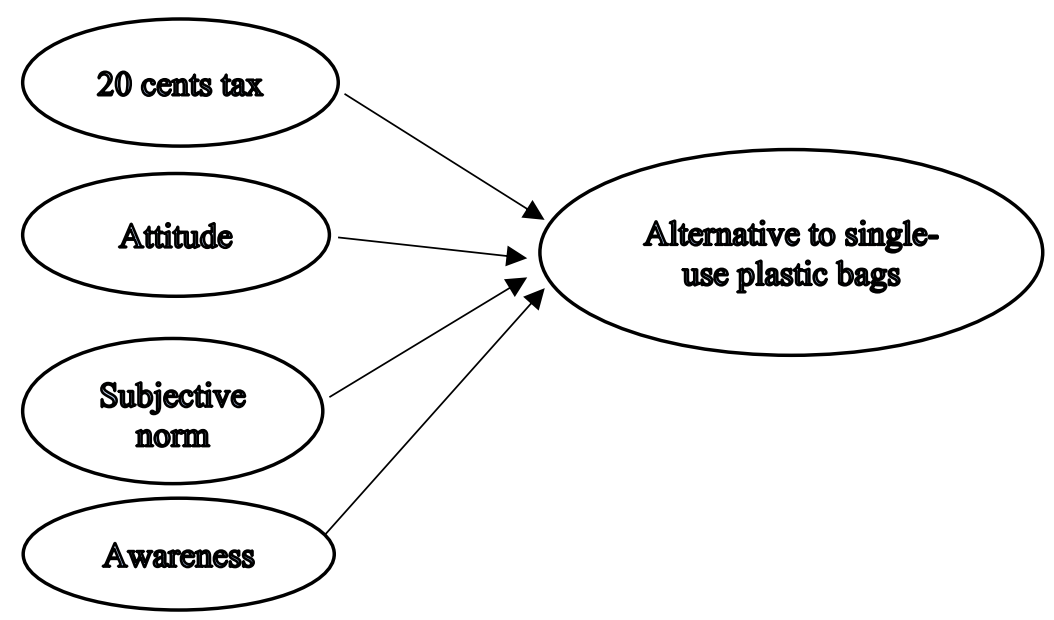

Figure 1: Study's proposed structural model

\section{Attitude}

An attitude was defined as a person's favourable and unfavourable feelings towards an object and tends to last over a longer period of time. Attitude influences an individual's choice of action, and responses to challenges, incentives, and rewards (Arslan et al., 2012; Sudarmadi et al., 2001). According to Ajzen (1985), an individual is more likely to undertake a certain behavior if he/she has a positive attitude toward undertaking the behavior. Numerous studies support the positive relationship between consumers' attitudes and behavioral intentions for green purchasing in different cultures, such as Asian, US, and European, and in different product categories, such as organic foods and timber-based products (Kalafatis et al., 1999). Studies (Zen et al., 2013; Jakovcevic, 2014) showed that the plastic bag charge was effective in risen people's attitude and habit in bringing their own bag. This tax resulted in an increment in bringing their own carrier bag use that was sustained even after months of executes. This indicated that the financial incentive may have triggered environmental motives by making people bring their own bags and that some consumers support charges that are aimed to improve environmental quality. This indicates that the behavior of bringing their own shopping bag can be sustained even without a reward system, as the behavior change is at least partly motivated by attitudes factors. Thus, this study proposed hypothesis 2 as follow: Hypothesis 2 (H2). Attitudes factor has a significant and positive effects on the use of alternatives to single-use plastic shopping bags.

\section{Subjective Norms}

Subjective norm reflects one's perceived social pressure to perform a certain behavior. If consumers believe that significant others think the use of an alternative to the single-use plastic bag is good, consumers will have more intention to perform this behaviour. Subjective norm has a significant effect on behavioral intention in the context of behavior related to green consumer behavior (Bamberg, 2003; Kalafatis et al., 1999). Ari et al (2016) demonstrated that social norms have a significant effect on the willingness to use cloth bags. Similarly, Ohtomo and Hirose (2007) showed that, within the scope of recycling behavior, behavioral intention is influenced by subjective norms. The study has established that individuals who support the banning of plastic bags intend and perform the behavior to 
reduce plastic bag use. Pro-environmental banning may have an impact on an individual's intentions and behavior. Kuppusamy and Gharleghi (2015) showed that, subjective norms and perceived behavior, are the two factors that were found to be significantly positive towards environmental behavior development. Based on the above literature, this study applies subjective norm as the perceived behavioral expectation from society, friend, parents, and the environment which influence an individual that changes their behavior toward the use of an alternative to single-use plastic bags and hypothesizes the following:

Hypothesis 3 (H3). Subjective norms have a significant and positive effects on the use of an alternative to single-use plastic shopping bags.

\section{Awareness}

Consumers' awareness of environmental issues is measured in terms of how people perceived the seriousness of issues forward, covering both general and specific issues. Somanathan et al (2009) showed that taxes on economic goods can lead to more consumer awareness of the negative environmental effects caused by them. Apart from the evidence from environmental taxation, where a tax on plastic bags reduces their usage, the mere provision of information to consumers about the demerits of plastic bag usage can have a significant effect as well. Kamaruddin and Yusuf (2012) mentioned that most of the respondents showed positive reactions towards the program regardless of the educational background and concluded that "white pollution" has reduced and the level of awareness of towards the environment the households especially in Selangor was increasing. The campaign has made people understand better the environmental harm caused by plastic bags and indirectly educated people about the consequences of disposing of plastic bags inappropriately, thus reducing the usage of plastic bags. Hence, this study hypothesizes that:

Hypothesis 4 (H4). Consumers' awareness of the environmental issues has a significant and positive effects on the use of alternatives to single-use plastic shopping bags.

\section{Methodology}

A survey with convenience sampling was used as a sampling technique which is frequently chosen by researchers for its simplicity and its periodic quality. Data were collected using the shopping mall intercept method with a self-administered questionnaire from the major shopping malls in Bangi and Putrajaya. With this method, it is easier to encourage someone already in a mall to participate in a study in comparison to emailing someone and trying to convince them to participate. Of the 167 responses collected, 150 valid responses were used for empirical analysis. A total of 61.3 percent of the respondents were female and the mean age was less than 25 years.

\section{Measures}

After a comprehensive and detailed literature review was conducted, the critical factors affecting the use of alternatives to single-use plastic bags are depicted in Table 1 . The questionnaire was comprised of two sections. The first section consisted of respondents' personal information. While in section two consisted of the main part of the questionnaire. Section two was categorized into five groups by the following variables: Alternative to singleuse plastic bags (ASUPB), 20 cents charge/ tax (20c), consumers' attitude (ATT), subjective norms (SNORM), and environmental awareness (AWARE). Table 1 shows the mean scores for each of the items for each construct. The questionnaire consisted of a total of 23 items 
defined on an interval scale from 1 (strongly disagree) to 5 (strongly agree). The data was administered by computer in such a way that the final total sample emerged from sampling. The results and data for each consumer were then processed according to the planned statistical analysis that was performed using SPSS version 25.0 and Amos 26. The statistical program SPSS was used for tabulation and the Cronbach alpha been used to check construct's reliability, and eliminating those items with a total-corrected element lower than 0.5 (Sekaran \& Baugie, 2013). There are no items that had to be removed. Descriptive analysis was used to illustrate the basic analysis of the data. Then the development of the research model was carried out through the confirmatory factor analysis (CFA) and structural equation model (SEM) using AMOS 26.

Table 1: Measurement scores

\begin{tabular}{lll}
\hline Items & Mean & SD \\
\hline Use an alternative to single-use plastic bags (ASUPB) & & \\
I bring own recycle bag while shopping. & 3.62 & 0.880 \\
I do not use single-use plastic bags because this is better for & 3.75 & 0.785 \\
environment. & & \\
I bring own recycle bag while shopping. & 3.62 & 0.880 \\
I use trolley while shopping. & 3.75 & 0.785
\end{tabular}

\section{0 cents charge/ tax (20c)}

I think the plastic bags charges campaign is at the right time. 3.66

\section{Attitudes (ATT)}

I think supermarkets or shopping outlets should use paper 3.97

bags instead of plastic bags.

I do not feel good using so much plastic bags.

$3.77 \quad 0.778$

I think plastic bags are more convenient.

$3.75 \quad 0.802$

I use plastic bags. It's the done things.

3.65

0.705

I don't think plastic bags are a big problem.

\section{Subjective norms (SNORM)}

Parents setting example for me.

Following friends' decision when shopping.

Teachers taught about it in curriculum lessons.

Newspaper, Magazine, etc.)

\section{Awareness on environmental issues (AWARE)}

I think plastic bag is non-biodegradable item.

I avoid using plastic bags because it will end up in landfill. 
Manufacturing plastic bags creates greenhouse gasses that 3.64

contribute to climate change.

It's wasteful to take new plastic bags.

\section{Results and Discussion}

\section{How effective is $\mathbf{2 0}$ cents charge?}

Table 2 shows about 76 percent of consumers said not to use plastic after the implementation of 20 cents charge on plastic bags. Consumers have chosen to bring their own shopping bags $(31.3 \%)$, hand carry $(24.0 \%)$ and, use trolleys (20.7\%). This study found 56 percent of consumers use less than 5 plastic bags per week which shown a good indicator for the effectiveness of the program.

Table 2: Alternative use to Single-Use Plastic Bags

\begin{tabular}{|c|c|c|}
\hline Questions & Frequency & Percent (\%) \\
\hline \multicolumn{3}{|c|}{$\begin{array}{l}\text { Do you use ALTERNATIVE to single-use } \\
\text { plastic bags after implementation RM0.20 } \\
\text { plastic bags charge? }\end{array}$} \\
\hline Yes & 114 & 76.0 \\
\hline No & 36 & 24.0 \\
\hline \multicolumn{3}{|c|}{$\begin{array}{l}\text { If "YES", what will you use in order to save } \\
\text { your } 20 \text { cents? }\end{array}$} \\
\hline Bring your own bags & 47 & 31.3 \\
\hline Hand carry & 36 & 24.0 \\
\hline Use trolley & 31 & 20.7 \\
\hline \multicolumn{3}{|c|}{$\begin{array}{l}\text { How many plastic bags do you use per week } \\
\text { after implementation the policy which is } \\
\text { each plastic bag charge RM } 0.20 \text { ? }\end{array}$} \\
\hline None & 16 & 10.7 \\
\hline Less than 5 & 84 & 56.0 \\
\hline 5 to 10 & 6 & 4.0 \\
\hline More than 10 & 34 & 22.7 \\
\hline Not sure & 9 & 6.0 \\
\hline
\end{tabular}

\section{Measurement and Structural Model}

Before estimating the structural model, confirmatory factor analysis (CFA) was conducted to examine the characteristics of the measurements. The CFA result suggested an excellent model fit, $\chi 2(94)=129.100, p<0.010, C F I=0.92, \mathrm{TLI}=0.89, \mathrm{RMSEA}=0.050, \mathrm{SRMR}=0.05$. The SEM result demonstrated a good model fit, $\chi 2(94)=129.100, p<0.010, C F I=0.92, T L I=$ $0.89, \mathrm{RMSEA}=0.050, \mathrm{GFI}=0.904 \mathrm{H} 1$ and $\mathrm{H} 3$ were supported. There is a significantly positive relationship between a 20 cents charge and alternative to single-use plastic bags $(H 1)(\beta=$ $0.272, p<0.05)$, as well as subjective norms $(\mathrm{H} 3)(\beta=0.552, p<0.01)$. Interestingly, the relationship between attitudes and alternative to single-use plastic bags was not statistically significant ( $\beta=0.36, p=0.231$ ); thus, $\mathrm{H} 2$ was rejected. Moreover, the results showed that there was not significant relationship between awareness on environmental issues and 
alternative to single-use plastic bags $(H 4)(\beta=-0.534, p<0.092)$. Thus, $\mathrm{H} 4$ was not supported. A summary of the hypotheses is listed in Table 3.

Table 3: Result of hypotheses testing

\begin{tabular}{|c|c|c|c|c|}
\hline Hypothesis & b & $\begin{array}{l}\text { Std. } \\
\text { error }\end{array}$ & & Result \\
\hline H1: 20 cents charge $\cdots>$ ASUPB & 0.272 & 0.128 & $0.034^{*}$ & Supported \\
\hline H2: Attitude $-->$ ASUPB & 0.360 & 0.301 & 0.231 & Rejected \\
\hline H3: Subjective norms ${ }^{--\cdot}>$ ASUPB & 0.552 & 0.178 & $0.002 *$ & Supported \\
\hline H4: Awareness $\cdots$ > ASUPB & $\begin{array}{l}- \\
0.534\end{array}$ & 0.317 & 0.092 & Rejected \\
\hline
\end{tabular}

Notes: * significant at 0.05

Based on the theory of Reasoned Action (Fishben \& Ajzen, 1975) and observations in various studies (Zen et al., 2013; Jakovcevic, 2014), this study investigated the consumers' alternative use of plastic bags on shopping, and then the following academic contributions were obtained:

a. The findings confirmed that the theory of reasoned action proposed by Ajzen (1969) indicates that subjective norm significant positively influences consumer behavior on using alternatives to the plastic bags during shopping.

b. (Martinho, 2017; Zen et al., 2013) indicated that there is a significant relationship between plastic bags charge and behavioral change. This study demonstrated that 20 cents tax strongly affected consumer usage of alternatives to plastic bags.

c. The finding shows a different with the results of Somanathan et al (2009); Kamaruddin et al (2012) who showed how consumers' awareness will reduces plastic use behavior.

d. The finding indicated that attitude exerted a non-significant influence for the case of using alternatives to a plastic bag. This result is in line with previous finding by Kuppusamy and Gharleghi (2015). Further investigation is needed to determine how 20 cents charge affects directly consumer attitudes and awareness of environmental effects.

Finding verified the results of how effective the charge of 20 cents toward the use of singleuse plastic bags while shopping. The result agrees with Zen et al. (2013) regarding consumer use of alternative to plastic, demonstrating the influence of tax on changing consumer behavior. The finding shows that the 20 cents charge or tax implementation actually increased the use of alternatives to single-use plastic bags while shopping. This result was also supporting the study of Revers et al (2016) which found the positive impact of the tax policy on behavioral changes. The tax was highly effective in encouraging people who already used reusable bags to utilize them more frequently. While forcing shoppers to pay extra for plastic bags might help to educate them, the RM 0.20 charge will end up in the coffers of retailers, increasing their profits at the expense of the public. However, the availability of plastic bags could also be counter-productive as consumers still choose to continue using them even though they are unhappy about having to pay RM 0.20 extra. Therefore, there are still 24 percent of consumers willing to pay 20 cents for convenience purposes. Subjective norms are connected with the use of an alternative to a single-use plastic bag. This implies that social influences, such as recommendations by relatives or friends and media advertisements sponsored by reputable, environmentally oriented parties, can increase consumer intention 
to use alternatives to plastic bags while shopping. Findings just suggesting that, awareness factor is significant but not strong enough to support behavioral changes in white pollution. This is the duty of the government to facilitate more environment-related advertising in the media to educate and enhance consumers' knowledge and awareness for environmental protection. Governmental organizations must promote in-school education programs and promulgate green policies and environmental protection. In line with the Malaysian Roadmap towards zero single-use plastic bags 2018-2030, thus it is important to emphasize consumers' knowledge regarding global warming and the white pollution issues which can be advertised in the media, which enabling consumers to understand the importance of environmental protection and green consumption. However, this study was not supported Thomas et al (2016) which reviewed a result of changing attitudes on using own shopping bags. Although no support was found for positive attitude spillover, the study indicates as a continuous program for enhancing consumers' awareness about the importance of using alternatives to single-use plastic bags for the environment may produce positive spillover effects in longer term.

\section{Conclusion}

In conclusion, a study concluded from a survey which showed that the plastic bag ban with 20 cents charge has been accepted by more and more people in Malaysia. Based on the sample in this study, the single-use plastic shopping bags usage has actually successfully being reduced by more than three-quarters following the implementation. Charging reasonably for plastic bags in hypermarkets and supermarkets has successfully decreasing plastic bags usage. This paper also mentioned that the policy is crucial and effective as the policy is indeed supported by the public. The plastic bag charges as a mechanism to change consumer behavior in using it need to be coupled with an educational and awareness programs. In order to promote this behavior, the government should cooperate with associated organizations to provide better awareness through appropriate channels, especially social media. As presented in this article, governments have the most responsibility with regards to managing zero single-use plastic bags, yet have limited authority to shift responsibility back onto the producer. As a result, state governments increasingly have adopted ordinances that embrace strategies seeking to reduce the consumption of single-use bags at the point of retail sale primarily by banning and levying fees. After all the responsibility to eliminate single-use plastics waste from the natural environment has to be shared by all the stakeholders including the government, industries, civil society, and the consumers.

\section{Limitations and Future Research}

The findings of this study should be considered in light of its limitations, which may also offer future research opportunities. The study identifies theoretical and methodological limitations which warrant further research. This study examined four determinants of consumers' behavior as an extended theory of TRA in regard to the use of alternatives to single-use plastic bags. In future studies, other factors and their interactions could be added. Subjective norms is the strongest determinant. This finding is consistent with and supportive to the marketingorientation concept which focuses on external factor as a major determinant of consumers' behavioral change in the consumer behavior field. The 20 cents charge is an important driver of consumers' behavior, therefore future research can use qualitative methods to investigate factors that formulates shoppers' behavior. From the aspect of environmental policy, the analysis has shown that the significant influence of 20 cents charges in behavioral changes. 
From the analysis, it can be defined, how the tax can give the most optimum result in reaching the aims of environmental policy. The costs of reducing pollution may differ according to the polluters and technologies. Therefore, the taxes are suitable for reaching the optimal level of pollution with the lowest costs. Future studies may expand with the exploration of consumer willingness to pay for the use of single-use plastic bags as a value for environmental protection. Other factors such as sociodemographic are only used as control variables in this study, and their interactions with user behavior are not addressed. Future research could examine these effects by improving the empirical theoretical design. The results of any future multi-variable analysis also can be improved by increasing the total number of participants.

Additionally, from a methodological standpoint, while the unit of analysis in this paper was the consumers in general, future research can conduct a comparative analysis between locations, or any other variables with regard to behavior. Such comparative analysis would enable decision makers in this area of white pollution to identify gaps in the behavior between respondents' background and demographic characteristics. Qualitative research is also applicable, as understanding consumers' behavior in regard to use alternatives to single-use plastic bags is still in the early stages. The study also guides the government on how to identify the paths required for formulating consumers' behavior.

Due to the time limitation, the results of this study were obtained from questionnaires from two areas in which the conclusions can provide a partial understanding of consumers' behaviour and it is difficult to represent the whole Malaysian. Thus, future surveys could be expanded to a more representative sample of a country. As research relies heavily on convenience sampling, participants are not randomly selected, then the results cannot be generalized to larger populations. Therefore, future research should apply other methods such as a longitudinal study which can overcome this constraint by providing a reflective understanding.

\section{References}

Ajzen, I. (1985). From intentions to actions: A theory of planned behavior. In J. Kuhl \& J. Beckmann (Eds.), Action control from cognition to behaviour. hlm 11-39. Berlin, Germany: Springer.

Akulian, A., Karp, C., Austin, K., \& Durbin, D. (2006). Plastic bag externalities and policy in Rhode Island. Environmental \& Resource Economics, 38, 1-11.

Ari, E., \& Yilmaz, V. (2016). Consumer attitudes on the use of plastic and cloth bags. Environment, Development and Sustainability, 19(4), pp.1219-1234.

Arslan, T., Yılmaz, V., \& Aksoy, H. K. (2012). Structural equation model environmentally conscious purchasing behavior. International Journal of Environmental Research, 6(1), 323-334.

Asmuni, S., Hussin, N., Khalili, M. J., \& Zain, M. Z. (2015). Public Participation and Effectiveness of the No Plastic Bag Day Program in Malaysia. Procedia-Social and Behavior Science 168. Pg 328-340.

Azemi, A., Palil, M. R., Amir, M. A., \& Said, M. S. (2019). Cukai Alam Sekitar: Pelaksanaan, Penjagaan Alam Sekitar dan Sistem Cukai yang cekap. BITARA International Journal of Civilizational Studies and Human Sciences. Vol 2, Issue 4.

Baker, A. R. (2010). Fees on plastic bags: Altering consumer behavior by taxing environmentally damaging choices. Expresso. http://works.bepress.com/alicebaker 
Bamberg, S. (2003). How does environmental concern influence specific environmentally related behaviors? A new answer to an old question. Journal of Environmental Psychology. Vol. 23 No. 1, pp. 21-32.

Chan, R. Y. K., Wong, Y. H., \& Leung, T. K. P. (2007). Applying ethical concepts to the study of "green" consumer behavior: An analysis of Chinese consumers' intentions to bring their own shopping bags. Journal of Business Ethics, 79(4), 469-481.

Convery, F., McDonnell, S., \& Ferreira, S. (2007). The most popular tax in Europe? Lessons from the Irish plastic bags levy. Environmental and Resource Economics, 38(1), 1-11.

Fishbein, M. (1967). Attitude and the prediction of behaviour. In M. Fishbein (Ed.), Readings in attitude theory and measurement. New York, NY John Wiley \& Sons. 477-492.

Fishbein, M., \& Ajzen, I. (1975). Belief, Attitude, Intention and Behaviour: An Introduction to Theory and Research, MA: Addison-Wesley.

Hong, L. C. (2011). Environmental tax laws in Malaysia today. Malaysian Accountancy Research and Education (MAREF) Review, 1(2), 9-10.

Hurriyet. (2015). It is being forbidden to use plastic bag in European Union Countries. http://www.hurriyetdailynews.com

Jakovcevic, A., Steg, L., Mazzeo, N., Caballero, R., Franco, P., Putrino, N., \& Favara, J. (2014). Charges for plastic bags: Motivational and behavioral effects. Journal of Environmental Psychology, 40, pp.372-380.

Kalafatis, S., Pollard, M., East, R., \& Tsogas, M. H. (1999). Green marketing and Ajzen's theory of planned behaviour: a cross-market examination. Journal of Consumer Marketing. Vol. 16 No. 5, pp. 441-60.

Kamaruddin, R., \& Yusuf, M. (2012). Selangor Government's 'No plastic Bag Day' Campaign: Motivation and Acceptance Level. Procedia - Social and Behavioral Sciences, 42, pp.205-211.

Kuppusamy, M., \& Gharleghi, B. (2015). 'No Plastic Bag Day' Concept and Its Role in Malaysian's Environmental Behaviour Development. Asian Social Science, 11(18).

Martinho, G., Balaia, N., \& Pires, A. (2017). The Portuguese plastic carrier bag tax: The effects on consumers' behavior. Waste Management, 61, pp.3-12.

MESTECC. (2018). Malaysia Roadmap Towards Zero Single-Use Plastics 2018-2030. Towards a sustainable future. Ministry of Energy, Science, technology, Environment \& Climate Change Malaysia.

Muthu, S. S., Li, Y., Hu, J. Y., \& Mok, P. Y. (2011). Carbon footprint of shopping (grocery) bags in China, Hong Kong and India Atmospheric Environment, 45 (2) (2011), pp. 469-475

Ohtomo, S., \& Hirose, Y. (2007). The dual-process of reactive and international decisionmaking involved in eco-friendly behavior. Journal of Environmental Psychology, 27, 117-125

Park, J. (2009). The search for an other way to shop. Packaging News(FEB.), pp. 28-29.

Poortinga, W., Sautkina, E., Thomas, G. O., \& Wolstenholme, E. (2016). The English plastic bag charge: Changes in attitudes and behaviour. Cardiff: Welsh School of Architecture/School of Psychology, Cardiff University.

Sekaran, U., \& Bougie, R. (2013). Research Methods for Business: A Skill-Building Approach. 6th ed. John Wiley \& Sons Ltd.

Somanathan, R., \& Gupta, K. (2009). Understanding the consumer demand for plastic bags in India- evidence from an experiment in Delhi. Delhi School of Economics. 
Soares, C. D., Milne, J. E., Ashiabor, H., Kreiser, L., \& Deketelaere, K. (2010). Critical Issues in Environmental Taxation. International and Comparative Perspective Vollume VIII. Oxford University Press. New York.

Siddique, R., Khatip, J., \& Kaur, I. (2008). Use of recycled plastic in concrete: A review. Waste Management, 28, 1835-1852.

Sudarmadi, S., Suzuki, S., Kawada, T., Netti, H., Soemantri, S., \& Tugaswati, A. T. (2001). A survey of perception, knowledge, awareness, and attitude in regard to environmental problems in a sample of two different social groups in Jakarta. Environment, Development and Sustainability, 3, 169-183.

The Star. (2019). Ensuring accountability in 20sen plastic bag charge. https://www.thestar. com.my/metro/metro-news/2019/11/01/

UNEP. (2018). Single-use plastics: A Roadmap for Sustainability.

World Bank Institute. (2008). Improving Municipal Solid Waste Management in India: A Source-book for Policy Makers and Practitioners, Washington, D.C.: World Bank.

WRAP. (2015). WRAP announces new carrier bag figures. 24th July 2015. Banbury: Waste and Resources Action Plan.

Zen, I. S., Ahamad, R., \& Omar, W. (2013). No plastic bag campaign day in Malaysia and the policy implication. Environment, Development and Sustainability, 15(5), 1259-1269. 